\title{
LA PANDEMIA Y EL ESTADO AUTONÓMICO
}

\author{
Francisco Balaguer Callejón \\ Catedrático de Derecho Constitucional, \\ Universidad de Granada
}

Cómo citar este artículo / Citation: Balaguer Callejón, F. (2021). La pandemia y el Estado Autonómico. Tudela Aranda, J. (coord.)

Estado Autonómico y covid-19,

Colección Obras colectivas, Fundación Manuel Giménez Abad, Zaragoza.

DOI: https://doi.org/10.47919/FMGA.OC21.0205

SUMARIO: I. VALORACIÓN GLOBAL DE LA RESPUESTA DEL ESTADO AUTONÓMICO A LAS EXIGENCIAS DE LA CRISIS - 1. Cuestiones metodológicas previas - 2. Una apreciación inadecuada de la crisis sanitaria y del derecho de emergencia - II. APROXIMACIÓN A LOS PROBLEMAS PLANTEADOS POR LOS DOS MODELOS DE ESTADO DE ALARMA - III. LÍMITES DE LA CAPACIDAD DE LAS COMUNIDADES AUTÓNOMAS PARA INCIDIR SOBRE DERECHOS Y COMPETENCIAS - IV. VALORACIÓN DE LAS RELACIONES INTERGUBERNAMENTALES DURANTE LA PANDEMIA V. LECTURAS PARA EL FUTURO

I. VALORACIÓN GLOBAL DE LA RESPUESTA DEL ESTADO AUTONÓMICO A LAS EXIGENCIAS DE LA CRISIS

\section{Cuestiones metodológicas previas}

Una cuestión que tenemos que plantearnos con carácter preliminar es la de la provisionalidad de cualquier valoración en el momento actual. Estamos ante una temática en curso de desarrollo, con un final todavía incierto, por lo que resulta imposible emitir un juicio basado en todas las variables que hay que considerar. Es verdad que existe ya material suficiente para señalar algunos de 
los problemas que se han planteado hasta ahora, pero la historia no ha terminado todavía. Por poner un ejemplo reciente, las críticas hacia la Unión Europea por la gestión de las vacunas quizás pueda verse desde otra perspectiva dentro de unos meses si, efectivamente, antes del verano se vacuna a un porcentaje significativo de la población europea y se recupera una cierta normalidad.

Quizás la tarea de reconstruir lo que ha pasado durante estos meses termine recayendo en los historiadores, que tienen vocación y oficio acreditado para generar narrativas a partir de la confusión general de los hechos. Los juristas estamos habituados a contrastar con parámetros. No tanto a reconstruir los hechos para describir su sentido cuanto a utilizarlos como material que nos permita extraer conclusiones jurídicas.

Aquí se presenta un segundo problema metodológico ¿cuál debe ser ese parámetro? En otras materias y en otras ocasiones hemos realizado comparaciones del Estado autonómico con Estados regionales o federales (Italia, Alemania, Austria, por ejemplo) para determinar qué fórmula descentralizadora ha sido más efectiva o para extraer lecciones que nos sirvan para afrontar un problema concreto. También hemos contrastado las respuestas del Estado autonómico con Estados unitarios (Francia, Portugal, por ejemplo) con la misma finalidad de aportar luz a las cuestiones que se nos han presentado en el desarrollo del modelo autonómico.

En relación con la gestión pública frente a la crisis sanitaria ¿con quién nos comparamos? No parece que tenga lógica alguna introducir aquí la variable de descentralización territorial para compararnos con otros países porque ha habido de todo, desde Estados Federales que han funcionado de manera catastrófica, como es el caso de los Estados Unidos de Trump o el Brasil de Bolsonaro, hasta Estados unitarios a los que tampoco les ha ido especialmente bien, como Francia o Portugal cuyos datos son equiparables, en términos generales, a los de España, Italia o Alemania.

Si queremos hacer una comparación que sea productiva tendremos que irnos a otras latitudes geográficas: por ejemplo, Taiwán, con un total de 9 muertos desde que comenzó la pandemia hasta finales de febrero de 2021 (en una población de 23 millones), o Corea del Sur, con menos de 1600 (en una población de 51 millones). Podría decirse que es una cuestión de naturaleza 
cultural (debido a determinadas peculiaridades de la cultura oriental) y hay quien ha intentado basarse en esos criterios para explicarlo, pero eso no sirve para el caso de Australia, por ejemplo, con menos de 1000 muertos desde que comenzó la pandemia (en una población de 25 millones).

Una última consideración que tenemos que tener en cuenta es la del contexto en el que se ha desarrollado la respuesta del Estado autonómico ¿Habría sido la misma en condiciones de mayoría absoluta del partido o la coalición que sustenta al Gobierno de la Nación? ¿Lo que estamos valorando es el funcionamiento del Estado autonómico como tal o los problemas coyunturales que se han planteado no por una determinada estructura del Estado sino por una configuración concreta del sistema político estatal en el momento en el que la pandemia se ha desarrollado?

Como se puede ver, son muchas cuestiones que dificultan una valoración ajustada de la respuesta del Estado autonómico a la pandemia. Nos movemos en un terreno muy inestable en el que algunas variables coyunturales pueden haber sido determinantes y en el que, además, resulta difícil realizar una apreciación con pleno conocimiento de todos los datos y con la perspectiva que ofrece el tiempo. Sin embargo, esa reflexión provisional es necesaria, aunque se quede a mitad de camino y con el lastre de estos condicionantes. Siempre podrá ser útil para comprender lo que está pasando y para ofrecer orientaciones de futuro que permitan mejorar las dinámicas políticas y constitucionales en una nueva situación de crisis de la envergadura de la que estamos experimentando.

\section{Una apreciación inadecuada de la crisis sanitaria y del derecho de emergencia}

En este asunto de la pandemia, hay básicamente oscuridad y niebla. Los mecanismos jurídicos y constitucionales han sido utilizados a partir de una apreciación inadecuada de la crisis sanitaria y del derecho de emergencia. Lo segundo va con lo primero: no todos los dirigentes políticos en todos los niveles, ni los operadores jurídicos de todos los territorios, han comprendido la gravedad de la situación desde el principio o en el curso de su desarrollo hasta ahora. De ahí la tentación que algunos han tenido de hacer política partidista de la pandemia y de eludir los compromisos que hubieran sido necesarios para poder limitar sus terribles efectos. 
Esto lo vemos también en la ciudadanía, como muestran los datos de las sucesivas olas de la pandemia, que evidencian una conducta imprudente en algunos sectores de la población, ciertamente minoritarios. Un comportamiento en el que hay responsabilidad individual, pero también pública. Una responsabilidad pública que no puede limitarse a la reproducción de mensajes morales apelando a la sensatez de la ciudadanía, en lugar de cumplir con las obligaciones legales de vigilancia, control y sanción de las conductas que contribuyen a expandir la epidemia.

Durante la primera fase de la pandemia, hace ahora un año, la falta de información y de medios de prevención podían justificar una cierta flexibilidad y tolerancia por parte de las autoridades. Sin embargo, ahora que hay medios de prevención que se pueden utilizar y sobre los que se puede exigir a los incumplidores que hagan uso de ellos, resulta injustificable la permisividad que podemos ver cada día en todos los niveles de gobierno en relación con el control efectivo del cumplimiento de las normas de distanciamiento social.

Ha habido, desde el principio, una distorsión en el análisis de la situación y de lo que exigía en cuanto respuesta a la pandemia, que todavía sigue existiendo. Esa distorsión ha ido unida a una situación política inestable en la que el Gobierno no cuenta con mayoría, la oposición no ha prestado el apoyo necesario y las CCAA han hecho de la gestión política de la pandemia una reivindicación esencial, que ha condicionado el apoyo parlamentario al Gobierno por parte de algunos partidos nacionalistas e independentistas. El contraste entre la excepcionalidad y el dramatismo de la situación, y la "normalidad" con la que algunos dirigentes la han abordado, resulta difícil de entender.

Partiendo de la ausencia de una percepción clara de la naturaleza de la crisis, es comprensible que se haya generado también una cierta dificultad para apreciar la dimensión de su tratamiento jurídico. En primer lugar, en relación con la naturaleza de las facultades propias del derecho de emergencia y con la declaración del estado de alarma por parte del Gobierno. A ellas nos referiremos más adelante. En segundo lugar, respecto de las competencias de las Comunidades Autónomas y del Estado para afrontar la crisis, sobre las que se ha producido una confusión inicial que se mantiene hasta el presente. 
La confusión inicial es la de que una pandemia de esta naturaleza es una cuestión sanitaria cuya gestión corresponde a las Comunidades Autónomas. Se han mezclado así dos cuestiones diferentes: la del origen del problema y la del modo de resolverlo. La crisis exige, por su origen, una respuesta basada en criterios científicos y epidemiológicos, pero no se resuelve solamente a través de las competencias autonómicas de gestión sanitaria. Requiere de una intervención masiva sobre el conjunto de la sociedad para evitar los contagios mediante medidas de distanciamiento social y otras muchas de carácter socioeconómico y de alcance internacional y europeo.

Es desde luego una confusión incomprensible porque basta con ver la incidencia que la pandemia está teniendo a nivel mundial sobre todas las esferas de la vida de los seres humanos y sus derechos fundamentales para comprender que las competencias autonómicas sobre gestión sanitaria no son suficientes para atraer hacia ellas las múltiples vertientes de lucha contra la covid-19.

Por si la facultad constitucional del Gobierno para declarar el estado de alarma no fuera suficientemente indicativa, bastaría con mirar someramente los títulos competenciales del Estado en la Constitución para darse cuenta de la cantidad de competencias que le corresponden al Estado y que deberían haber dado lugar a una ordenación política muy diferente de las medidas contra la pandemia.

La pandemia ha afectado a todos los sectores de la vida de las personas y de la propia actividad estatal, comenzando por las relaciones internacionales y siguiendo por prácticamente todos los ámbitos pensables de la acción pública. Naturalmente esto no quiere decir que el Estado no tuviera que coordinarse con las Comunidades Autónomas ni tampoco quiere decir que en la respuesta a la pandemia la preservación de la vida y la salud de las personas no deba ser el principio fundamental al que debe someterse la actuación de todos los poderes públicos en todos los niveles de gobierno y, por tanto, el ejercicio de las competencias que le correspondan al Estado o a las CCAA.

Precisamente por eso, porque en una situación de gravedad extrema en la que salvar la vida y la salud de las personas exigía desde el principio coherencia y unidad de acción en esferas más propias de una economía de guerra que de la mera gestión sanitaria, es por lo que los niveles superiores de gobierno son los 
que tienen que intervenir. Sin perjuicio de que el nivel internacional debería haber funcionado mejor y habrá que pensar en reformas futuras en ese nivel que refuercen a la OMS e impliquen a más agentes, lo cierto es que el nivel prioritario debería haber sido el europeo, como ha ocurrido con las vacunas. A este respecto, si tenemos en cuenta las limitaciones competenciales con las que opera, las iniciativas que está desarrollando la Comisión Europea, pasada la primera etapa de desconcierto, parecen bastante razonables, especialmente por lo que se refiere a la promoción de una "Unión Sanitaria Europea" y a la necesidad de abordar igualmente reformas futuras en el nivel europeo.

Como se pudo ver ya desde el principio, cuando comenzó a perfilarse la gravedad de la crisis sanitaria, la solución a la pandemia pasaba:

- Por una logística específica, propia de una economía de guerra, con la orientación de una parte de la producción industrial hacia la fabricación masiva de instrumentos sanitarios esenciales, desde pruebas de detección del virus a respiradores, pasando por mascarillas y otros medios de protección. Esta no es una competencia de mera gestión sanitaria.

- Por una logística específica también para el mantenimiento de la producción de bienes básicos y la prestación de servicios esenciales, teniendo en cuenta el alcance de los confinamientos que serían necesarios, hasta tanto se pudiera disponer de los medios que permitieran contener la propagación del virus y reducir la sobrecarga hospitalaria. Esta no es una competencia de mera gestión sanitaria.

- Por una ordenación económica y presupuestaria en el marco de la Unión Europea que, con sustento europeo (como el que finalmente se obtuvo a través del Plan de Recuperación) permitiera hacer frente a la crisis económica derivada de la pandemia. Esa ordenación ha estado condicionada en todo momento por las medidas adoptadas para luchar contra la pandemia, de manera que de la eficacia de esas medidas depende también el alcance de la crisis económica. Por tanto, habría sido más que razonable que ambas políticas, la sanitaria de lucha contra la pandemia y la económica de lucha contra la crisis, estuvieran concentradas o, cuando menos coordinadas de manera efectiva. Esta no es una competencia de mera gestión sanitaria. 
- Por una serie de medidas con incidencia directa en los derechos fundamentales de las personas, que afectan a todas las esferas de la vida: confinamientos, toques de queda, restricciones de circulación, obligación de portar mascarillas, entre otras muchas. Esta no es una competencia de mera gestión sanitaria.

En definitiva, ha faltado y sigue faltando todavía una percepción real del alcance de la pandemia, que se ha desvinculado de su origen sanitario y que debe ser combatida en todos los ámbitos de acción pública relevante para poder afrontarla. Al mismo tiempo, en su dimensión sanitaria, la limitada competencia sobre gestión sanitaria ha terminado por atraer al ámbito competencial de las Comunidades Autónomas la capacidad de decisión sobre una gran parte de las medidas que son necesarias para luchar contra la pandemia y que se encuentran fuera de la gestión sanitaria y se enmarcan dentro de las competencias que le corresponden constitucionalmente al Estado.

\section{APROXIMACIÓN A LOS PROBLEMAS PLANTEADOS POR LOS DOS MODELOS DE ESTADO DE ALARMA}

Sería necesario realizar también en este punto algunas consideraciones previas sobre las situaciones de crisis y el derecho de emergencia. La Constitución ha establecido unas reglas para regular algo que en gran medida no admite regulación, como son las situaciones imprevisibles de la vida. Lo que hace nuestro ordenamiento en su regulación constitucional y legal es someter la acción pública a una serie de condiciones que son las propias del derecho de emergencia: provisionalidad de las actuaciones, proporcionalidad de las medidas y control político y jurisdiccional.

Así, el artículo 116.6 CE: "la declaración del estado de alarma no modificará el principio de responsabilidad del Gobierno y de sus agentes". Igualmente el art. 3.1 de la LO 4/1981: "los actos y disposiciones de la Administración Pública adoptados serán impugnables en vía jurisdiccional'. Del mismo modo, el art. 1.2 LO 4/1981: las medidas y su duración serán "las estrictamente indispensables para asegurar el restablecimiento de la normalidad" y "su aplicación se realizará de forma proporcionada a las circunstancias", así como 
el art. 1.3 de la misma ley: finalizada la vigencia del estado de alarma "decaerán en su eficacia cuantas competencias en materia sancionadora y en orden a actuaciones preventivas correspondan a las Autoridades competentes, así como las concretas medidas adoptadas en base a estas, salvo las que consistiesen en sanciones firmes".

En otros países de la Unión Europea no hay una ordenación constitucional del derecho de emergencia, aunque las decisiones que se han adoptado son similares a las de nuestro país ¿podríamos decir que esos países no son respetuosos con el Estado de derecho? Si para salvar vidas hay que adoptar medidas basadas en criterios científicos que restringen derechos fundamentales ¿pueden ser un impedimento las deficiencias del marco legal existente?

Hay que recordar aquí que el derecho de emergencia o derecho de necesidad ha sido tradicionalmente (y lo sigue siendo en gran medida) contra legem, precisamente porque se basa en un planteamiento antiformalista, para evitar que una interpretación formalista termine por impedir la consecución del fin superior perseguido, que en este caso es nada menos que preservar la vida de las personas en el contexto de una pandemia. Los reglamentos que se dictaban en virtud de este derecho se llamaban "de necesidad" justamente porque se partía de la base de que eran absolutamente necesarios, pese a contradecir las normas legales, para preservar bienes superiores como la vida o la salud de las personas.

La cuestión real que se ha planteado en nuestro ordenamiento es que, en una situación de debilidad del Gobierno, podría haber resultado imposible la prórroga del estado de alarma y, por tanto, la adopción de las medidas necesarias para combatir la pandemia. ¿Qué tendría que haber hecho el Gobierno si tal cosa hubiera ocurrido? ¿Permitir que se extendieran los contagios y que se colapsara el sistema sanitario provocando una letalidad mucho mayor de la que ya hemos sufrido como consecuencia del virus?

La conclusión es aberrante: una regulación constitucional que está orientada a canalizar la respuesta pública en situaciones de emergencia sitúa finalmente al Gobierno en peor posición que la de los sistemas constitucionales que no contemplan ordenación alguna. Mientras otros países estaban adoptando las medidas necesarias para preservar vidas y evitar el colapso del sistema 
sanitario, nuestro país habría quedado a merced de una regulación constitucional estricta de las funciones del gobierno y de un bloqueo derivado de la ausencia de colaboración por parte de la oposición parlamentaria.

Es cierto que finalmente la situación se pudo salvar con la colaboración de una parte de la oposición, pero someter a un país al espectáculo permanente de estar frente al abismo de la expansión incontrolada de una pandemia a falta de unos pocos votos en el parlamento es algo que no tiene ninguna lógica en el plano de los principios constitucionales. Un entendimiento antiformalista de las facultades, no sólo del Gobierno de la Nación sino de cualquier poder público frente a una situación de catástrofe sanitaria como la que estamos viviendo, resulta esencial.

Porque a este espectáculo lamentable han seguido otros igualmente incomprensibles derivados en gran medida de esta percepción formalista que condujo a la reforma de la LJCA para habilitar el control preventivo de las medidas que impliquen la limitación o restricción de derechos fundamentales, mediante un procedimiento de ratificación o autorización judicial. Desde esa perspectiva, no ha sido muy afortunada la disposición final segunda de la Ley $3 / 2020$, de 18 de septiembre, de medidas procesales y organizativas para hacer frente al COVID-19 en el ámbito de la Administración de Justicia (aunque el art. 2.3 del Real Decreto 926/2020, de 25 de octubre, por el que se declara el estado de alarma, ha dispuesto su no aplicación, mientras esté vigente, a las autoridades competentes delegadas de las CCAA en relación con las ordenes, resoluciones y disposiciones dictadas en el marco de lo previsto en los artículos 5 a 11 de ese Real Decreto).

Además de los problemas que plantea un control judicial de este tipo, el hecho de que distintos tribunales den respuestas diversas en el enjuiciamiento de las medidas adoptadas en una situación de emergencia sanitaria, resulta disfuncional por muchos motivos. Genera confusión, mina la legitimidad de los poderes públicos en un momento de crisis (en el que es más necesario que nunca que la ciudadanía cumpla con las normas y con las resoluciones de la autoridad) dificulta el cumplimiento de las indicaciones científicas para el control del virus y, en definitiva, genera obstáculos innecesarios a la finalidad esencial de luchar contra la pandemia. Todo esto tiene que ver nuevamente con una inadecuada percepción formalista de las funciones que corresponden a los poderes públicos frente a una situación de emergencia. 


\section{LÍMITES DE LA CAPACIDAD DE LAS COMUNIDADES PARA INCIDIR SOBRE DERECHOS Y COMPETENCIAS}

De acuerdo con lo que acabamos de afirmar y teniendo en cuenta las características del derecho de necesidad, el debate sobre la capacidad de las CCAA para incidir sobre los derechos en estas situaciones de crisis responde a una falsa polémica. El problema no es si las Comunidades pueden o no incidir sobre derechos. En una situación de emergencia no sólo pueden sino que deben: es su obligación, como la de cualquier poder público y cualquier ciudadano, hacer todo lo que sea necesario para proteger la vida y la salud de las personas. La cuestión no es esa, sino si resulta operativo, desde el punto de vista de la eficacia de las medidas, que se enmarquen dentro del limitado título competencial de la gestión de la sanidad.

El problema es que no habría sido necesario que las Comunidades Autónomas actuaran más allá del ámbito estricto de la gestión sanitaria si el Gobierno de la Nación, en un contexto político diferente del actual, hubiera podido desarrollar sus funciones con el sustento de la oposición y con la colaboración de las Comunidades Autónomas.

Pero las Comunidades Autónomas han querido asumir esas competencias para realizar una gestión política de la pandemia, lo que ciertamente entra dentro de la lógica del Estado autonómico. Sin embargo, una vez que han comenzado a ejercitarlas no siempre y no todas han asumido la responsabilidad de su gestión, sino que algunas han seguido haciendo responsable al Estado de las deficiencias que se han manifestado con la evolución de la pandemia. Esto forma parte también del juego habitual de la política en las relaciones entre Estado y Comunidades Autónomas, así que no debe extrañarnos y se deriva en gran medida de la propia existencia del pluralismo territorial, en condiciones normales. El problema es que, en el contexto de la pandemia, mientras ese juego se desarrollaba, la situación sanitaria adquiría dimensiones dramáticas que contrastaban fuertemente con el ejercicio normal de la política.

La percepción de que la muy limitada competencia de gestión de la sanidad de las Comunidades Autónomas ha terminado por expandirse como el propio 
virus, ahogando las competencias constitucionales del Estado, ha llegado al extremo de que en alguna resolución judicial se ha afirmado incluso que las CCAA sí pueden limitar derechos por sí mismas, pero no cuando aplican normas estatales dictadas en el marco de la competencia estatal sobre coordinación general de la Sanidad, establecida en el art. 149.1.16 ${ }^{\underline{a}}$ de la Constitución.

Es decir, el Estado ni siquiera tendría competencias sobre los derechos constitucionales en situación de pandemia porque le corresponderían a las Comunidades Autónomas en virtud de su competencia sobre la gestión de la sanidad. De nuevo la confusión entre el origen del problema y el modo de resolverlo. El origen es sanitario, pero no se resuelve solo en los hospitales ni siquiera primariamente en los hospitales, porque lo que hay que evitar es el contagio y eso no tiene nada que ver con la gestión sanitaria sino con otras variables que afectan al comportamiento de los individuos y de la sociedad, no a la gestión sanitaria.

Pero la cuestión no es sólo que las CCAA hayan asumido las competencias para el control de la pandemia a través de una interpretación expansiva de sus facultades de gestión sanitaria. El problema es que algunas han funcionado sin asumir su propia responsabilidad política por esa gestión e intentando trasladar al Gobierno de la Nación esa responsabilidad. En términos generales hemos visto durante la pandemia una "hiperresponsabilización" del Estado frente a una escasa atención a la responsabilidad de las Comunidades Autónomas en la gestión de la crisis.

Esto se debe en parte a una deficiencia estructural del Estado autonómico derivada de la sobredimensión del espacio público estatal frente al de las CCAA, lo que hace que del debate político se termine centrado siempre en el Estado. En parte está ocasionado también porque el discurso político de las CCAA tiende a alimentar esa sobredimensión al basarse en gran medida en la reivindicación frente al Estado y en la crítica al Gobierno de la Nación.

Esta retroalimentación es especialmente visible cuando se produce una confusión entre el nivel del pluralismo político y el del pluralismo territorial. Esto es, cuando los dirigentes autonómicos no se limitan a gestionar los intereses de sus territorios (como correspondería a la realización de un principio de pluralismo territorial) sino que actúan defendiendo intereses políticos 
específicos de sus partidos (en el marco del pluralismo político) aunque con ello puedan perjudicar los intereses de sus territorios y de su ciudadanía.

Ciertamente, resulta inevitable un cierto solapamiento entre pluralismo territorial y pluralismo político, pero el clima de crispación política ha favorecido esa confusión en algunas Comunidades Autónomas. De ese modo, han terminado por verse como normales actitudes políticas en las que se utiliza el poder territorial como plataforma para hacer una oposición constante al Gobierno estatal y no para gestionar, con un criterio político propio obviamente, la crisis sanitaria.

Podríamos decir, desde esa perspectiva, que ha habido un funcionamiento "normal" del Estado autonómico que contrasta fuertemente con una situación de catástrofe humanitaria. Esto ya lo dice todo. La primera lección que podemos extraer de la pandemia es que algunas de las dinámicas que se han desarrollado durante más de cuarenta años en el Estado Autonómico dificultan que pueda funcionar adecuadamente en condiciones extraordinarias. Pero tampoco sería justo limitar esa valoración al Estado autonómico porque, en realidad, casi todo ha funcionado así: desde los entes locales hasta el Poder judicial, pasando por una parte importante, aunque minoritaria, de la ciudadanía.

El caso paradigmático ha sido sin duda el populismo de los dirigentes de la Comunidad de Madrid o de los de la Generalitat de Cataluña, al menos hasta que se produjo el cambio en la Presidencia en esta última. Mientras la gravedad de la crisis alcanzaba dimensiones dramáticas, se dedicaban a hacer política partidista contra el Gobierno de la Nación. En las demás CCAA ha habido de todo, pero no podríamos decir que su gestión no haya estado orientada a resolver los problemas derivados de la pandemia, con aciertos y errores como los que también ha tenido el Gobierno de la Nación. Tanto el Gobierno estatal como los autonómicos han intentado hacer su trabajo lo mejor posible aunque dentro de esas condiciones previas de los vicios generados por las dinámicas del Estado autonómico. 


\section{VALORACIÓN DE LAS RELACIONES INTERGUBERNAMENTALES DURANTE LA PANDEMIA}

Por lo que se refiere a la gestión de las Comunidades Autónomas y su coordinación con el Gobierno, ha pasado de todo en este año que llevamos de pandemia. Es difícil poner orden conceptual, por decirlo así. De nuevo, puede decirse que ha existido un espíritu de colaboración en términos generales. Otra cosa es la ya indicada actitud de los dirigentes populistas, que han mantenido el enfrentamiento y la tensión con el Gobierno en todo momento. Las críticas que han realizado al Gobierno de la Nación han pasado por todas las etapas: se le ha criticado por acciones y omisiones, de manera contradictoria y a veces en el mismo discurso. Durante este año, el Gobierno ha tenido la culpa de lo que hacía, de lo que no hacía, de lo que no dejaba hacer a las CCAA y hasta de lo que dejaba hacer a las CCAA.

Hasta se le ha hecho responsable de lo que se sospechaba por los dirigentes populistas (sin fundamento aparente) que podría hacer o no hacer, ejercitando así una especie de petición de responsabilidad política preventiva. Posiblemente seguiremos con este comportamiento mientras dure la pandemia y quizás se convierta en una línea de conducta política permanente, al menos mientras las tendencias populistas sigan prosperando.

De cualquier modo, salvo en el caso de la Comunidad de Madrid y de la Generalitat de Cataluña (hasta el cambio en la Presidencia) se puede decir que las Comunidades Autónomas, sea cual sea su orientación política, han actuado de manera razonable en los términos de las reglas del juego previamente definidas. Esto no significa que no haya habido conflictos y tensión entre el Gobierno de la Nación y los gobiernos de algunas CCAA, especialmente cuando pertenecían a partidos diferentes. Esto forma parte de la tensión política normal, por más que a veces resulte extraño en una situación como la que estamos viviendo.

En todo caso, no se entiende muy bien qué sentido tiene que Comunidades Autónomas con los mismos parámetros sanitarios adopten medidas diferentes respecto de la apertura o cierre de negocios, el toque de queda y su horario, el cierre perimetral de localidades y otros ámbitos. Estas decisiones no forman parte del autogobierno de la Comunidad Autónoma, entre otras cosas, porque deberían estar condicionadas por criterios científicos y no políticos. 
La cogobernanza no responde a las exigencias científicas de la lucha contra la pandemia ni a motivos competenciales en relación con las facultades que debería ejercitar el Estado en una situación excepcional como la actual, en el marco del derecho de necesidad. Responde a criterios políticos de dirigentes territoriales que, comprensiblemente, quieren ofrecer también a la ciudadanía una gestión propia de la pandemia en un contexto de debilidad parlamentaria del Gobierno de la Nación.

Por otro lado, es innegable que la imagen de los primeros momentos de la pandemia, en la que solamente las autoridades estatales parecían participar en la lucha contra el virus tampoco resultaba compatible con el Estado autonómico y con las competencias de las CCAA, ni siquiera en un momento tan excepcional como el que estábamos viviendo y a pesar de todas las facultades que al Estado le puedan corresponder en una situación de emergencia.

Quizás la solución no sea ni el primer modelo ni el segundo, sino uno intermedio que haga posible una respuesta unitaria en todo aquello que sea necesario a nivel nacional, junto con la coordinación entre el Estado y las Comunidades Autónomas. Una coordinación que evite la capilaridad de las competencias así como las facultades de control preventivo que se les dio a los tribunales y que deberían eliminarse mediante la reforma de la LJCA (ya que su no aplicación prevista en el art. 2.3 del Real Decreto 926/2020 solo afecta a las medidas adoptadas por las autoridades competentes delegadas de las CCAA, no por las estatales, y mientras dure el actual estado de alarma).

\section{LECTURAS PARA EL FUTURO}

Desde una perspectiva constitucional no parece que hayamos aprendido gran cosa para el futuro. Buena prueba de ello es que seguimos con las mismas dinámicas un año después y no parece que se vayan a terminar. Si se produce una nueva pandemia, lo que va a determinar la respuesta que se pueda dar seguramente será más la situación política que la experiencia acumulada en esta. Naturalmente, sea cual sea la situación política, es previsible que algunas cosas se puedan hacer mejor. Por ejemplo, en materia de logística, garantizando que haya una reserva estratégica que permita dar una respuesta 
rápida en medidas de protección frente al virus o en la dotación de material sanitario a los hospitales.

Seguramente muchos errores se repetirían y hay motivos objetivos para que eso ocurra. España es un país turístico en el que el sector de la hostelería y la restauración tienen un gran peso en la economía. No es fácil para nuestro país cerrar las fronteras y adoptar medidas drásticas desde el primer momento para limitar la circulación de personas, controlar o cerrar las fronteras y confinar a la población.

Sin embargo, si nos sirve de algo la experiencia es para desear lo que seguidamente se expone, por si hubiera una nueva pandemia o una situación similar que en el futuro pudiera generar una tragedia de las dimensiones que estamos viviendo:

- Un Gobierno cohesionado y fuerte con mayoría suficiente en el parlamento.

- Una oposición responsable que deje a un lado su interés electoral en situaciones de crisis en las que hay que dar una respuesta unitaria a los problemas.

- Unas Comunidades Autónomas que, sin renunciar a sus opciones políticas, se presten a ayudar en lo que sea necesario, modulando la reivindicación competencial mientras dure la crisis.

- Unos tribunales que se centren en valorar la proporcionalidad y la necesidad de las medidas, asumiendo que se trata de aplicar un derecho de emergencia y que los criterios de interpretación deben de ser diferentes a los de una situación de normalidad.

- Unas autoridades que en todos los niveles cumplan con su obligación de hacer respetar la ley y de sancionar cualquier atentado contra la salud pública en proporción a su gravedad. Expresado de otra manera: unas autoridades que no pidan a los ciudadanos que cumplan con su responsabilidad, porque eso ya lo hace la inmensa mayoría, sino que sancionen a los incumplidores, como ocurre en cualquier otro ámbito del ordenamiento jurídico.

- Una ciudadanía lo suficientemente responsable como para no seguir votando a dirigentes populistas que no tienen ningún respeto por la vida humana y que anteponen su ambición política o su ideario personal 
(cuando ambos no coinciden, que es lo usual) al interés público y a los derechos fundamentales.

La cuestión es si los desajustes tienen una respuesta posible desde el derecho o están excesivamente condicionados por la política. En realidad, tienen mucho que ver con la cultura política y constitucional. Habría que plantearse, por ejemplo, si es razonable que, después de cuarenta años de desarrollo del Estado autonómico, todavía siga existiendo una cultura política en la que el debate público se concentre casi exclusivamente en el nivel estatal. Esta sobredimensión del espacio público estatal, que responde a inercias históricas, no se ajusta a la distribución competencial actual y genera deficiencias importantes en el control político de los gobiernos autonómicos. No es un criterio de buen gobierno, porque favorece la sensación de impunidad y la deriva populista que desde hace años ha arraigado en algunas Comunidades Autónomas.

También sería necesario ajustar la relación entre pluralismo político y territorial. No es razonable que aquellas Comunidades Autónomas cuyos dirigentes comparten afiliación política con el gobierno de turno (sea cual sea el partido que esté en el poder) cierren filas cada vez que hay un problema político, anteponiendo sus intereses de partido a los del territorio (y generando así un desequilibrio a favor del pluralismo político y en perjuicio del pluralismo territorial). Tampoco lo es que la oposición política al gobierno se articule a través de las Comunidades Autónomas gobernadas por los partidos rivales, produciendo el mismo efecto de anteponer el pluralismo político al territorial en el ámbito autonómico.

Todas estas deficiencias del Estado autonómico, que llevamos arrastrando desde hace muchos años, nos dan una imagen distorsionada de la realidad política, y provocan un desajuste entre el ejercicio del poder y el control de ese poder, con la correspondiente exigencia de responsabilidad política. Las Comunidades Autónomas siguen siendo en nuestro sistema constitucional unos entes que responden más al esquema de la reivindicación política permanente frente al Gobierno de la Nación que al de instituciones democráticas normalizadas en las que los poderes públicos responden ante la ciudadanía, no sólo en los procesos electorales, sino de manera permanente, en el ejercicio cotidiano de sus funciones. 
En condiciones de normalidad, estas deficiencias terminan ajustándose al final y resultan tolerables dentro del contexto en el que se produce el ejercicio de la política. De hecho, en la mayor parte de las Comunidades Autónomas, a pesar de la ausencia de control político equiparable al nivel estatal, hay dirigentes muy conscientes de sus responsabilidades y un contexto político más funcional que el que se ha desarrollado en los últimos años a nivel estatal. Sin embargo, en situaciones tan excepcionales como las que estamos viviendo, estas deficiencias del Estado autonómico han resultado tremendamente disfuncionales.

La pandemia ha situado a los poderes públicos ante el espejo, como ha hecho con los propios ciudadanos. En lo que hemos visto hasta ahora ha habido de todo, desde la generosidad extrema de quienes han dedicado todas sus energías a salvar vidas humanas, hasta la imagen funesta del populismo que se está extendiendo por nuestro país, generado conflictos absurdos entre algunas Comunidades Autónomas y el Estado. Estamos viviendo un momento crucial en la historia de la Humanidad en el que la grandeza y la miseria han ido de la mano. De esta experiencia hemos aprendido algunas lecciones importantes para el futuro de nuestro país, que seguramente olvidaremos tan pronto como la pandemia termine. 